\title{
38
}

\section{ECOLOGICAL PUBLIC HEALTH}

\author{
Leaders, Movements and Ideas to Shift the \\ Boundaries Between the Normal and the Desirable
}

\author{
GEOF RAYNER AND TIM LANG
}

\section{Abstract}

Tony McMichael's 1999 essay, 'Prisoners of the Proximate: Loosening the Constraints on Epidemiology in an Age of Change', published by the American Journal of Epidemiology, is the authors' starting place for understanding current thinking and challenges in public health. Rayner and Lang argue that McMichael's essay presents the case for ecological reasoning to be applied in epidemiology. In so doing, it opens the door for an appreciation of complexity as a developing theme in the sciences and arts and for the interdisciplinary enhancement of public health thinking, several lines of which are considered. The chapter then outlines the main traditions and models of public health among which a newer approach, ecological public health, sits. The authors explore the conventional models of public health and why they believe an ecological perspective on health has particular advantages. Their core argument is that human and ecosystems health is interdependent and that climate change, land, water, air, microbial activity, all show that, in the 21 st century, just as humans can no longer live by disregarding the health of ecosystems, nor can they continue with the fantasy, expressed through neoliberal thought, that individual desires, behaviours, consumption and ultimately patterns of health can be disconnected from the health of everyone and everything else. The cause of public health, they conclude, requires not only movements but also leaders. 


\section{Introduction}

Knowing is not enough; we must apply. Willing is not enough; we must do. (Johann Wolfgang von Goethe) ${ }^{1}$

In his essay, 'Prisoners of the Proximate', Tony McMichael gives an overview of the history and changing shape of epidemiology, concluding with an appeal for modern epidemiology to embrace an ecological public health conception (McMichael, 1999). We agree with that analysis and have argued the case from different starting points elsewhere (Rayner and Lang, 2012). In this chapter, we explore a key feature of ecological public health thinking - the centrality given to addressing complexity. The argument is that ecological thinking helps public health by accepting the normality of complex interactions while also explaining the necessity of multiple rather than single interventions or actions. Ecological thinking ought to be normal within public health, but it is not. To understand why not partly requires an historical look at the public health project. Other models of public health appeared to provide the answer, offering quicker fixes, narrower foci. In that sense, ecological public health does not make life easier for proponents!

The present chapter sets out to put the return of interest in complexity into historical context, arguing that it is the modern manifestation of a long-established approach to knowledge. This chapter then outlines the other main traditions and models of public health among which ecological public health sits. These emerged in the 19th and 20th centuries, as ill health became a dire result of industrialisation. We explore the advantages the models offer and why we believe an ecological perspective on health has particular advantages, yet why it makes public intervention apparently harder. Our core argument is that today ecological thinking becomes central, simply because the interconnection of human and ecosystems health is now self-evident. Climate change, land, water, air, microbial activity, all show that humans cannot live in an ecosystemsfree bubble, even if they think they can. And yet the 20th century nurtured a fantasy that human health could somehow be disconnected. This is both poor science and poor politics and policy. It translates and corrals public health into a fantastic pursuit of private or personalised health.

1 www.iep.utm.edu/goethe, accessed 10 April 2015. 


\section{Complexity}

Could anyone dispute that we live in an age of complexity? The notion is not, however, new. In the 16th century, William Shakespeare held his largely illiterate audience spellbound by his dramatic interweaving of historical narrative and psychology. Among the many claims for the sophistication of Shakespeare's literary work, it has been argued that his last great play, The Tempest, anticipated Darwinian evolutionary ideas (Love, 2010). Two centuries later, Johann Wolfgang von Goethe, remembered more today as a playwright than as a biologist (and a passionate advocate of Shakespeare), presented an evolutionary view of natural biology, arguing that art, poetry and science were interlinked and complementary. While his biological formulations differed considerably from Darwin, his admirer, the anatomist, Hermann von Helmholtz, claimed that Goethe's biological writings led to an accelerated acceptance of Darwinian science (Richards, 2006). Goethe's near contemporary, the French biologist, Jean-Baptiste Lamarck, a decorated soldier, may himself have lacked his counterpart's artistic pretensions (although he worked with botanic artists), but his influence was equally, or perhaps more, profound. He proposed that all organisms evolved from simple to complex forms due to their ability to pass on acquired changes to their offspring. Lamarck not only brought the word 'biology' into formal use, but set the dimensions of European evolutionary thought in the early 1800s (Corsi, 2005).

Nevertheless, it was only through the English naturalist, Charles Darwin (or more correctly, through Darwinism, since this attribution includes the codiscoverer of natural selection, Alfred Russel Wallace), that due scientific rigour was applied to the problem of how species changed and differentiated. Darwin revered Goethe and learned much from Lamarck, but the conceptual threads of his reasoning drew from a far broader intellectual cloth (Herbert, 2005). For Darwin, as for Goethe, nature was a thing of wonder. His concluding metaphor in On the Origin of the Species was a poetic description of an 'entangled bank' of nature where numerous organisms interacted 'in so complex a manner' (Darwin, 1859).

In contrast, the modern beginnings of the story of public health did not start with biology, even less, evolutionary biology, and although biomedical understandings of health and disease played a role, and were later to play the starring role, other perspectives and frameworks of action initially mattered more. The figure of Edwin Chadwick, journalist, researcher, lawyer, civil servant, close observer of Paris's revolutionary health scene, and philosopher's apprentice (to Jeremy Bentham), despite more recent criticisms (Hamlin, 1998), sets the scene for a quintessentially modern view of public health. Chadwick saw 
public health as a task of administration and environmental change more than of ministration to bodies, and further proposed that, technically, improvement was more an issue of improved sanitary engineering than of medical knowledge.

This is not to say that advances in biology and biomedical thinking at the population level played no part. Edward Jenner, the countryside General Practitioner, certainly exemplified that by modernising the ancient practice of immunisation. John Snow, too, is today celebrated as the founder of epidemiology (and voted by the readers of a medical magazine in 2003 as the 'greatest doctor' of all time). But their impact can be considerably overplayed. The worth of vaccination was hotly disputed until early in the 20th century (Williamson, 2007). And Snow's celebrity reputation was only established decades after his death (Vandenbroucke et al., 1991).

One reason why Thomas McKeown's critique of the role of medicine in improving public health has continued to scandalise supporters of the medical model of public health is not just because he considered biomedical interventions to have a more limited impact (until the 20th century) than claimed, but because he thought that the primary factors for improving population health lay only at the boundaries of formal public health action, and because he advocated the view that economic advancement and nutrition were key to public health improvement, a fundamentally Malthusian argument (McKeown, 1971). Such views later opened him to the charge that he paved the way for policy groups who argued that economic growth was the primary (not just a significant) pathway to improved public health (Szreter, 1988, 2002). On the contrary, we see such techno-economic perspectives in public health as only one specific mode of advance.

In fact, few celebrated figures in the history of ecological thought, apart from Wallace, had much or anything to say about human health, despite the pressing health circumstances they doubtless would have observed. Wallace, while wholly on the side of 'sanitary science', was highly critical of public health interventions of his day, like Jenner's vaccination (Weber, 2007). Their presence in this chapter's celebration of ecological public health is not specious. These thinkers and writers provide scientific and imaginative underpinnings for what must surely be a mainstream approach to public health today. Our argument here is that public health thinking does not need to be embarrassed by this rich intellectual history. On the contrary, it offers the perfect and broad canvass of ideas from which to critique the fetishisation of evidence-based interventions or a reductionist biomedicine. Public health thinking is, and always must be, a ferment of ideas, not just evidence. Furthermore, even a brief discussion of the origins of modern biology and ecological thought allows us, in a very different era, to understand that neither the consideration of complexity nor ecology is especially new, that art, science and creativity might, indeed must, coexist, 
and that, as Goethe exemplified, a more participatory comprehension of nature must substitute for one based on technological dominance and subservience. As bacteria teach us, they might initially be vanquished, only to defeat our powerful drugs later.

\section{Ecology Addresses Complexity}

Darwin may be associated with creating the foundations of modern ecology but he nowhere used the word, his own term of choice was 'the economy of nature', a term with roots in Linnaeus's botany and used by political economists and others of his day. By the turn of the 20th century, the new term had come to substitute. Coined by Darwin's German follower, Ernst Haeckel, its broadening acceptability may be due, in part, to the loss of focus on nature among economists and towards consumer notions of utility and desire (Schabas, 2005). Consumerism and the 'dismal science' of economics have systematically marginalised nature, other than as resources to be mined (often literally). Haeckel may be a mostly forgotten (even vilified) figure today - with detractors and defenders (Richards, 2007) - but his specification of ecology as an integrative science of species and environments remains relevant, even if the use of the term is confused by its association with the consumer products industry.

Complexity, for Darwin, is what occurs when species interrelate in their environmental setting, and he uses the term constantly. No 'balance of nature' was implied - as is the appeal today of much nature conservancy in a tradition of thought extending back to the ancient Greeks (Kricher, 2009) - but rather an unending process of dynamic interplay. A Darwinian understanding underlies all modern biology, and much of what is also called ecological thought, but it was another half-century after his death before the principles of natural selection were synthesised with the newly discovered science of genetics (after the rediscovery of Mendel's ideas in 1900) and the model - if not the detail became complete. Complexity, unlike ecology, is no neologism. It draws from the Latin complexus, meaning to entwine, encircle or to be 'twisted together'.

Despite its extensive use by Darwin, its entry into scientific vocabulary is actually recent. Philosopher of science, Nicholas Rescher, notes that the term is absent from standard philosophical dictionaries and encyclopaedias, and even absent from most systems of metaphysical thought (Leibnitz, C. S. Peirce and A. N. Whitehead are seen as the 'honourable exceptions'; Rescher, 1998). Among complexity theorists, it is, of course, central, although in substance shifts according to topic or disciplinary field. Nevertheless, there are unifying properties. Complexity, says information scientist, John Holland, is 'emergent', always in a state of coming into being (Holland, 1998). It has been seen as the 
'start position' from which evolution began (Lauterbur, 2005). Even if the fundamental laws governing the universe turn out to be simple (or rather, uncomplex), argues Nobel-winning physicist, Murray Gell-Mann, given that chance and indeterminacy exist (as introduced by quantum mechanics), complexity is always expansive (Gell-Mann, 1995).

For members of the multidisciplinary Santa Fe Institute (Gell-Mann, Holland and colleagues), complexity theory has offered a unifying systems-based perspective extending across life and non-life. It is constrained by start positions, dynamic relationships between parts, conditions of scale and systemic feedback. It forms a complement and corrective to the reductionist perspective that studies parts in isolation. In this picture, complexity is both an assessment about the changing fabric of reality (emergent, hyperbolic, etc), as well as a perspective on that reality. The principle of complexity offers a new conceptual basis not just for biology, physics and chemistry, but has implications that extend across all disciplines and areas of life, including health, public policy, cultural theory and more (Philippe and Mansi, 1998; Taylor, 2001; Tsoukas and Hatch, 2001; Geyer, 2003; Mitleton-Kelly, 2003; Pearce and Merletti, 2006; Rickles et al., 2007; Sandro et al., 2009; Geyer and Rihani, 2010).

Complexity may seem central to ecological thought, but the word 'ecology', since Haeckel invented it, has come to span dozens of specialist fields and overlapping and even antagonistic assumptions and methodologies. In considering natural ecology, for example, species interactions underlying complexity can be both antagonistic, involving predation, herbivory and parasitic, or mutualistic, such as involving the pollination of flowers by insects (Montoya et al., 2006). Some biologists stress the calculable properties of interrelationships, where, for example, the 'level' of complexity is presented as the number of entities and interconnections in a given system, as well as the effect of the entities on the system. In this manner, Edward O. Wilson has described complexity as 'the search for algorithms used in nature' (Wilson, 1998, p. 95). At this point, it might be useful to remember Goethe's complaint about mathematicians that they declared 'everything as worthless, inexact, and insufficient which cannot be submitted under their calculation' (Simms, 2005). The big question of how far the rules of biological complexity applied to human behaviour intrigued Darwin. Certainly since Darwin himself, there have been both influential thinkers and movements that have offered a more direct equation. There has also been an equally forceful movement claiming that while humans undoubtedly have biological roots, they now have autonomy from those roots.

Beginning with the Darwin-influenced philosopher, Charles S. Peirce (as mentioned by Rescher, above), it has been suggested that while all organisms require some minimal level of signalling of their presence to other organisms, human communication operates through far higher-level principles. Recent 
evolutionary anthropology has suggested that human cooperative and reflective modes of behaviour were first established through group foraging, with positive feedback loops between organic reconstruction, cognitive development and behavioural modernisation, the result being a continuous development of the human learning niche and the building of cultural inheritance (Sterelny, 2012). Society today operates far beyond the level of the group. The technologies, social processes and institutions that make up the world can only be conceived in their full extent through abstractions, constructs and models; systems that operate beyond the capacities of any single individual to understand. Human society has therefore become complex, not simply due to biological evolution or its extensions into culture (like the notion of memes), the laws of physics or, in some recent economic formulations, the evolution of the economic market, but because human society - through its art - makes it so (Dissanayake, 2009). More than through science perhaps, it is the richness and creativity of art and culture, as presented by Shakespeare or by Goethe, which is perhaps the most visible and engaging aspect of human complexity.

This, too, is an ecological perspective, but one that draws on an extension of the principle of Darwinian complexity into the cultural realm, as found, for example, in philosopher John Dewey's opposition to the Cartesian dualism found in much contemporary Western philosophical thought (Popp, 2007). Dewey once remarked: '[w]e have no word by which to name mind-body in a unified wholeness of operation' (Dewey et al., 2008, p. 27). Following Dewey, the modern task is not just to free analysis from biological reductionism, but its economic, psychological or sociological counterparts as well. Engaging with human complexity entails the recognition that human existence is constructed through multiple levels and interactions: material, biological, social and cultural. Thus, while culture grants people meaning and values, a fact that may account for humankind's recent and rapid evolutionary progress, compared to other species, at the same time, people are biological agents and recipients existing in a permeable relationship with others. It is because human society operates through multiple planes of complexity that even the most apparently private matters of health at all times reveal a parallel public health counterpart.

The systemic and complexity-based view of ecology first presented by Darwin and Wallace was later complemented by the concept of the ecosystem, introduced by Arthur Tansley early in the 20th century (Tansley, 1935). This concept reconfirmed that systemic thinking was essential, and that while ecosystems existed in variations of scale and density, no ecosystem could be understood in linear or reductionist terms alone. More recently, it has been proposed that quite minor, apparently confined perturbations in ecosystems and subsystems might lead to dramatic regime shifts, a feature that undermines classical approaches in mathematical ecology (Norberg and Cumming, 2008). 
Ecological and complexity-based thought in the mid-20th century expanded through an heterogeneous mix of disciplines and thinkers. The British-American economist, Kenneth Boulding, presented the case for an integrated systemsbased perspective reaching across the sciences, necessary, he thought, because of a trend towards the disintegration of scientific communication. Although thinking 'a general theory of practically everything' implausible, he presented the case for interdisciplinary systems theory. In effect, this was a multilayered conception of complexity expressed through a hierarchy of eight frameworks conveying varying principles, ranging from the clockworks of physics and astronomy, the control mechanism of cybernetics, the self-maintaining structure of cells and on to purposive behaviour and self-awareness of social animals (Boulding, 1956). His lasting contribution was perhaps the revival of an older specification of the economy with the recognition of natural limits, now known as ecological economics.

René Dubos, the French-American biologist, discovered gramicidin in 1939, the world's first commercially produced antibiotic. If he is chiefly remembered today as an ecological theorist rather than scientist, it was his ecological perspective on biotechnology and nutrition futures - now proved essentially correct - that warranted his reputation. Dubos observed that if society was not cautious about the use of antibiotics, bacteria would evolve according to the Darwinian principles operative in the rest of nature to get round them. In similar terms, he warned of the shift in diets, with consequences for trends in chronic disease. All human development involved evolutionary dynamics, he argued, but the critical factor in shaping disease response was the environmental conditions that undisciplined technology creates' (Dubos, 1968, p. 219). In other words, the poor use of powerful medicines and the marketing of processed foods provided the new aberrant - while seen as normal - conditions for disease to flourish. If only his ecological warnings had been taken seriously. Today, the situation of antimicrobial resistance is alarming (Spellberg et al., 2008; WHO, 2011).

Jay Forrester, known today as a management theorist, developed his perspective from the study of electronics systems. He argued that common intuitive judgements about cause and effect relationships failed to acknowledge the existence of feedback, either in production systems or, for that matter, in urban environments. The tendency was to consider issues in linear terms. Although people looked for links between cause and effect, Forrester argued that causes might not be proximate in time and space to witness the full resultant effects. What Forrester called 'system dynamics' established an approach to complexity that encompassed counter-intuitive behaviour, growth limits, non-linearity, tipping points and feedback - the latter term drawn from his electronic experience. In the hands of Donella Meadows and colleagues, Forrester's systems dynamics formed the basis of The Club of Rome study in the 1970s, repeated 
some years later, which modelled environmental stress against population growth, in the style of a vastly expanded Malthusian logic (Meadows et al., 1972, 1993).

Outwardly, Forrester's enterprise appeared utterly technocratic, but in essence the conclusion of his research was that there was no purely technical solution to the challenge of creating a sustainable society. Of these three, only Dubos offered a centrally public health focus, but the thinking of all three converged around points of system complexity, developing mismatch, a critique of technological consumerism and the promotion of sustainable patterns of living. These themes remain critical for the public health project today.

\section{Models of Public Health: Different Approaches}

Much of modern ecological thought, although not all of it, as we have shown, flows back to the Darwinian intellectual struggle to understand the interrelationships of living forms and the dynamics of change. Darwin memorably offered the 'entangled bank' as a simile for the interplay of visible and invisible life forms that collectively manifested themselves as an English hedgerow and roadside bank. His focus was on flora and fauna, rather than societal or cultural levels of existence. In our book, Ecological Public Health, we have suggested that while ecological thinking offers brilliant hope for analysing complexity, it has tended to be segmented into competing areas of discourse: the natural world and the social world. Indeed, many people in the public health world think ecological thinking is synonymous with the social-ecological model, often associated with the psychologist, Urie Bronfenbrenner (Bronfenbrenner, 1979). This is regrettable, as good public health requires analysis and the infrastructure for both. Instead, we propose a heuristic for re-integrating those two levels of analysis (Rayner and Lang, 2012). Reality may be viewed through four coexisting dimensions: (i) the material or physical; (ii) the biological and physiological; (iii) the cognitive or cultural; and (iv) the social dynamics of human interaction. Viewing problems through this multidimensional lens helps describe complexity while providing structure and pointers for actions. It offers a way of applying ecological public health in the modern world.

There are four definable and conventional models with which this ecological public health model competes (Lang and Rayner, 2012; Rayner and Lang, 2012). These models are: the sanitary-environmental and biomedical models, the rising social-behavioural model and the less discussed techno-economic model. 


\section{Sanitary-environmental model}

The sanitary-environmental model is what most originally thought public health action to be. It focuses on the health of populations in their physical circumstances. It might equally be called the classical model of public health, for some of the measures with which it is associated are ancient, such as the laying of water pipes, sanitary engineering and the like. The Romans were its original masters.

In the 19th century, the challenge was to clean and clear up urbanisation and industrialisation's dirt and detritus - seen as the determinants of epidemic disease - and to rid society of nuisances to eye, ear and nose. Its advocates were known as sanitarians or hygienists. Its professionals were public health inspectors, engineers, town planners, building standards regulators, even street designers. In the richer parts of the world, these measures are now taken for granted, being embedded in law and convention. Infrastructure is governed by tight rules and highly organised arrangements for managing human, biological and material flows and waste.

Looking outside those societies that first industrialised, a different picture emerges. While such environments represent the modern equivalent of early 19th-century European cities, they operate on a much larger scale. Here, the model should thrive, as in Europe before it, but the model relies on the institutionalisation of material processes of change and an enabling political system. It required not only apprehensiveness about the consequences of inaction but also imagination and foresight - the appreciation that sewage did not need to swill in the streets or that deaths due to infectious disease could, and indeed should, be averted. Critically, it also required ample reserves of economic and political capital, perhaps only feasible during times of economic growth or political democratisation.

\section{Biomedical model}

This model comes in two, sometimes ill-at-ease, versions, one with a population orientation, the other an individual orientation. Population-based biomedical interventions first came into prominence in the early 1800 s with vaccination, and much later through the establishment of public health laboratories. In its modern form, promoted by the English physician, Edward Jenner (1749-1823), vaccination was claimed as more scientific, more effective and with fewer side effects. (It had been in use in China over centuries.) Vaccination was probably the first example of the internationalisation of a biomedical public health measure. Today, vaccination has a powerful track record. In 1980, the World Health Assembly announced the eradication of smallpox. 
In contrast, a more personalised version of the biomedical model now shapes our understanding of how the living body works and fails to work. From the 1880 s, medicine began to cast aside ineffective treatments. It was only after the close of that century that, with the increasing use of aseptic techniques, postsurgical survival rates began to climb. After World War II, progress has been exceptional, but comes with a warning, and at great cost. In the 1960s, social epidemiologists like Thomas McKeown provided controversial reminders that improving nutrition was a more salient factor for health than medicine.

The case example is the USA. In the 1950s, the USA spent 4.4 per cent of gross domestic product (GDP) on healthcare, a low figure because, as William Schwartz of the Brookings Institution says, in those days 'doctors really couldn't do much' (Schwartz, 1998). The USA subsequently invested massively on devices and technologies ranging from the iron lung to computerised imaging (Rothman, 1997). In 2009, 17.4 per cent of US GDP was spent on health care, double highincome country averages. By 2040, it could rise to 30 per cent (Fogel, 2008). Despite these immense costs, unaffordable for all but the richest countries, US health-care arrangements remain socially fractured by access and outcome inequalities - and attempts to reform this situation deeply contentious; it is also deeply inefficient overall, the USA ranking only 37th out of 191 in international performance rankings (OECD Health Data, 2011). Many treatments improved vastly over time, but no amount of spending could halt the mounting scale of US diabetes or obesity, a result of its 'society design' more than any other factor. A fresh equation has seemingly taken root, that medicine, to quote political scientist, Aaron Wildavsky, equals health (Wildavsky, 1976).

\section{Social-behavioural model}

This model seems new, but is not. Rulers have attempted to influence the behaviour of their people for health reasons for centuries. King James of England and Scotland published a diatribe against tobacco in 1604 (Stuart, 1604). The model is older yet, when religious precepts that explicitly or implicitly include health, such as towards washing, or choice or preparation of foods, are included. The social-behavioural model is now the main rival to the biomedical model. It addresses the behavioural circumstances of health. Thus, since the 1950s, smoking, food and nutrition, and physical activity, increasingly are seen as major factors in chronic disease prevention, clinical areas where the biomedical model struggles.

Here, public health is engaged with rules and guides to behaviour. Early 20thcentury social science focused on the undirected modernisation of behavioural rules over matters like eating, defecating, nasal blowing, spitting, etc, via the analysis of social-psychological mechanisms like embarrassment and shame. 
If the royal court once decided such rules, increasingly the state, commerce and civil society assumed this role, and in a more intentionally directive manner (hence, 'nanny statism').

In the 19th century, newly mass-manufactured products were marketed with health messages, catering to an increasingly segmented consumer marketplace, like products for women. Personal health habits were changed by messages such as the value of regular bathing of bodies, cleanliness of the home and about women's domestic responsibilities and work. These were salutary. Today, the marketing firepower of transnational corporations is massive. In work done for the World Health Organization, we have shown that Coca Cola can spend more annually on its marketing of soft drinks than the entire biannual budget of the World Health Organization (Lang et al., 2006).

Ranged against the power of commerce, what leverage do public health advocates possess? What methods do they use? Is it psychology, marketing - reborn as social marketing (with pitiful budgets)? Or is it law? The Canadian public health writer, Nancy Milio, expressed it well in the mid-1970s. It could only be a 'minimal aim', she said, to make healthy choices easier: the unhealthy choices must also be blocked. And for the most widespread impact, the focus should be on 'national-level policy-making' which would in turn change 'the range of options for the largest number of people' (Milio, 1976). Oddly, the recent analytic focus on behaviour reunites public health and economics (the latter as 'behavioural economics'), which begets the latest fad, 'nudge', with the hidden ideological charm being that the state should do something (warn people, edit choices), but not much (Thaler and Sunstein, 2008; Rayner and Lang, 2011).

\section{Techno-economic model}

The techno-economic model is central in the public health literature but undesignated as a type, and deeply controversial to some historians, who have seen it as an attack on public health measures. It depends on two concepts: economic growth and knowledge growth.

Economic growth leads to a higher standard of living, which then leads to better nutrition. This was a view promoted by the social epidemiologist, Thomas McKeown, and, following him, by the Nobel Prize winning economist, Robert Fogel (who has named his version 'technophysio evolution') (McKeown, 1976; Fogel, 2004). Both hark back to political economists, Adam Smith and Thomas Malthus, on the economy of nature (as noted, for which the term 'ecology' later substituted), the former who indexed human prosperity to its rate of population growth and the latter who linked patterns of disease to population growth and agricultural productivity. Society's breakout from the 'Malthusian trap' is based 
heavily on knowledge. The conversion of knowledge into raised agricultural productivity and energy-heavy living and work technologies reduces physical stress on bodies and creates opportunities for easier, potentially richer lives.

There is no automatic link between economic growth and health. This may be so up to a basic level and depending on other factors, such as effective institutions, limited corruption, the rule of law and reasonable levels of democracy. The case for a link between improving standard of living and patterns of health is historically strong, but in the 21 st century, diminishing returns seem to have set in. The USA was once among the healthiest societies in the world but, with mounting social inequality, an inferior, poorly accessible health-care system and a thin social safety net, health trends are moving in the opposite direction (Komlos and Baur, 2004). A cornucopia of food or consumer goods - the basis of modern US culture and trend now spreading worldwide - hardly provides the automatic key to improving health and well-being.

\section{Ecological Public Health}

Our last model draws us back to our introductory themes of ecology and complexity. Ecology, as noted, is a term that denotes interrelations of species and of nature, but its meaning extends far beyond this, permeating across fields of enquiry and social movements. Early in the 20th century, the term 'ecology' was drawn into sociology, largely from botany, as a means of examining human behaviour and social forms in environmental contexts (Park and Burgess, 1925). It already was obvious in the century before that ecological thought did not have to be 'environmental', and that environmentalism was not the sole domain of ecologists, even if they were interested (and most, beginning with Darwin himself, were not). It was neither an environmentalist nor ecologist (noting that neither term then existed) but the economist, J. S. Mill, who first recommended a 'stationary state' economy to preserve the natural environment, and conversely it was the naturalist, Alfred Russel Wallace, who proposed that pollution and inequality were merely the opposite sides of unregulated capitalism. Their joint proposals for saving and democratising nature and human health involved the common ownership of land and cooperative production. Such influences might be seen as liberal or socialist in conception, but the revival of ecological thought in the current period also has taken its cue from Thomas Malthus, often seen solely as a reactionary figure in history. For example, in the mid-1960s, parasitologist, Leo Kartman, presented an ecological account of challenges to public health, drawing on Malthus's views on the natural limits to human development (Kartman, 1967). John Hanlon, US Assistant Surgeon General, drew on Kartman's and René Dubos's critique of technological change, thus marking the first advocacy of an ecological public health approach by an important 
public health official (Hanlon, 1969). Here was an ecological perspective in two dimensions: natural and human ecology, each with a feedback to the other, but it was also true that the historical line from Darwinian-inspired ecology to Hanlon's use of the term was anything other than straight.

Alongside an explicit formulation of public health as being desirably 'ecological', this was mirrored by the emergence of ecological thought within disease epidemiology. McMichael termed this process one of 'methodological consolidation', an intellectual journey which began in the 1600 s with the description and classification of death and disease, was bolstered by sanitarian theory in the 19th century, permutated into theories of specific cause and then onwards to broader causal models, to arrive at (in developed countries) a new public health context of rapidly declining infectious diseases and proportionally increasing chronic disease, an outcome, in the context of other intellectual developments we have noted, that spurred 'a more ecologic view of how the social and environmental conditions of life influence population health' (McMichael, 1999).

The implication was that epidemiology had become social epidemiology, which had then become ecological epidemiology. McMichael brought together a new stress on the environment, an appreciation of complexity, and other novel conceptual extensions, such as a life-course perspective. If his view of the new was a reassertion of the old, what was also seemingly apparent was that the determinants of health were increasingly delocalised, that understanding health amelioration required understanding of feedback effects - perhaps the first demonstration of which was made by $\mathrm{M}^{\prime}$ Gonigle and Kirby ( $\mathrm{M}^{\prime}$ Gonigle and Kirby, 1936) in the 1930s. He understood that behavioural and cultural factors in health, if long present, were taking on new forms, and that the signs of biological feedback, as Dubos warned in the 1960s, were beginning to present.

More than half a century on, and perhaps taking a cue from the magisterial Ottawa Charter (WHO, 1986), major bodies like the US Institute of Medicine support an ecological perspective on public health (Institute of Medicine (US) Committee on Health and Behavior: Research Practice and Policy, 2001; Institute of Medicine, 2002). The need to develop these ideas is urged on by hard evidence of major changes reshaping the conditions on which human health depends: rapid, massive population growth; climate change; resource scarcity and price volatility; soil, sea and freshwater damage; biodiversity loss. In the past, specifically environmental threats to human health were mostly localised, although infectious diseases rarely recognised borders. Today, that biological dynamic continues, witnessed by the ceaseless tendency for bacteria, as Dubos saw, to reduce the effectiveness of antibiotics. Another strand of change has a more material basis in the link between industry, energy use and toxicity, with a double impact, on the human species and on the rest of nature. A third strand 
is cultural and societal, shaped by changing mass behaviour and aspirations. In sum, although ecological public health has been articulated as a perspective, it has never been formulated systematically. Our argument is that this is precisely what is now needed to help reshape how societies live, to inform policy and to integrate the long-term into short-term political choices.

\section{Why Do This?}

Why not stick to the simpler, conventional public health models? The short answer is that they no longer capture what evidence demands of a policy framework - a mix of overview and capacity to inform detailed actions. So often, public health is caught in 'policy cacophony', confronting multiple explanations when the political system demands only one, preferably with immediate beneficial effects (Lang and Rayner, 2007). Modern ecological public health thinking is able to face complex and dynamic biological, material, social and cultural dimensions of the human, living and physical world. It works better than the other models considered, in a number of ways:

- It draws on these conventional models and plays to their strengths.

- It is the one model of the five that is fully integrative.

- Drawing on complexity science and system dynamics, modern ecological thinking introduces questions of non-linearity, variations in scale, evolutionary mismatch and biological feedback, and other emergent qualities of nature and human behaviour.

- Aiming to build knowledge for action, it eschews the narrow, backwardfacing, 'evidence-based' perspective.

- It engages multi-actor engagement: action is required by all.

- It is explicitly interdisciplinary, rejecting tiered and unequal multidisciplinary 'compartmentalism' - the critique derived from philosopher, John Dewey.

- It is interdimensional, incorporating the material, biological, social and cultural dimensions of life.

- It promotes the role of social movements in shifting and integrating public perspectives on health and politics. 


\section{How Ecological Public Health Helps Grapple With Reality}

Tony McMichael usefully described both the growing sophistication of epidemiology and the intransigence of proximal thinking. Of course, the opposition to effective public health measures, let alone ecological public health, goes much further. Why is the failure to advocate this ecological perspective on public health so important now? Because the world of policy is awash with huge problems, so big that political processes are in danger of seeming unable (or is it unprepared?) to address them. These issues include the obvious ones: non-communicable diseases, climate change, the fragility of ecosystem services (including biodiversity), but they also include feedback into animal, plant and human biology, of which antimicrobial resistance is merely one form. These are vast and complex issues, which invite either silence or symbolic action only from

policymakers. They are right; to tackle them requires not only vast expenditure and effort but also, as Dubos asserted half a century ago, the rethinking of economics linked to a certain technological and consumerist path. Given the short-termism of politics, it is much easier to park such issues than deal with them. Another reason is that the economy has primacy, an explanation that not only explained the historical delay in addressing pollution but today explains why nutrition-based diseases, such as obesity or diabetes, are addressed primarily on the basis of behavioural dimensions and not outcomes of business strategy and supply chains.

What progressive Victorians got right, in an age when mass political action was gaining sophistication, was the power of social movements and attempts to modify state structures newly sensitive to them. Of course, one should not sentimentalise such times. While the sanitarians achieved much in many important arenas of the health 'battle', other problems such as energy and pollution, and above all social inequality, were barely touched. Many actions in the name of health were also perceived, and some intended as repressive and socially judgemental. The veneer of reform in the name of health could sometimes barely disguise social contempt.

Today, if everything is so complex, as we and others argue, how it is possible to intervene in causation? We wonder, in fact, if the challenge today is really more difficult than 100 years ago. The scale, perhaps. As societies become more complex, the mechanisms for changing them or for scaling-up areas where progressive change has been won need to evolve to match. That is why models and conceptions of public health need to be updated; they must be appropriate for the times. Today, in an era when the warning signs of ecological damage are now so clear and so strongly evidenced, it is essential that this case is represented strongly in, and injected into, public health policies. The simple 
and central message that must be spread into policymaking processes is that human health and ecosystems health must be seen from within one unifying framework (Hancock, 2011). Longer time horizons must be set. Western energyguzzling societies, for example, will not shift from being high carbon emitters overnight; but Germany is showing the way with regard to its power sources, aiming for 45 per cent of energy to be sourced from renewable sources by 2030 (Schiermeier, 2013), and the UK ambitiously set a target in its Climate Change Act 2008 to reduce its $\mathrm{CO}_{2}$ emissions by 80 per cent by 2050 (Her Majesty's Government, 2008). Equally, societies that have seen supermarkets overflowing with food as symbols of success - banishing the Malthusian nightmare of excess population and underproduction of food - will not easily begin to shift their patterns of distorted eating and resulting diet-related ill health (notably obesity). Twenty-first-century ecological public health thinking must lengthen its time frames.

Another effect of subscribing to ecological public health thinking concerns the role of expertise. Medical models have consistently celebrated the specialist: the public health physician as detective, soothsayer and problem solver, all in one. Ecological public health, by contrast, necessarily draws on multiple disciplines and modes of action. This requires existing disciplines to have something not usually associated with public health - humility and preparedness to take difficult arguments seriously. If only more people had taken seriously the early warnings about overuse and the capacity of antimicrobial resistance to undermine the effectiveness of antibiotics, for instance. These miracle 'cures' were latched onto with joy by those who saw biology and nature as forces to be tamed, rather than worked within. Retrospectively, we can see, too, that the use of antibiotics coincided with a more consumer era for medicine. Where strict controls should have existed (as with pollution), their use instead was defined by choice. In this respect, ecological public health thinking easily can appear to spoil proffered advances. It cautions against potentially rebounding technical fixes and emphasises the need to think longer term about the possible consequences of intervention. More positively, it suggests the advantages of multiple, rather than single, lines of action. If ecological public health requires multidimensional analysis, actions are more likely to be effective if they are pursued across multiple dimensions of policy and action. To put it simply, combinations of intervention are more likely to have lasting effects, even if they are more difficult to parse into an evidence-based system of scrutiny over their impact. 


\section{Looking Ahead: What Difference Does This Make?}

Most obviously, ecological public health provides a rationale for reinvigorating the public health task. It redefines what is meant by the health of the public in the 21 st century. It redefines progress (Jackson, 2009). It proposes a rebalancing of emphasis on material wealth as the sole driver of life improvement by layering in more factors, more levels by which people's lives can be kept well. The evidence is strong that, beyond a certain basic level, wealth does not deliver endless health improvement. Indeed, inequalities may be more important than other prime factors (Wilkinson and Pickett, 2009). The ecological public health perspective goes further. It asks us to consider what is meant by progress itself. Is health the absence of disease? No, it is about well-being, and not just human but ecosystems health, too. And in an era where humanity has to face the consequences of two centuries of mining the Earth and the concentration of wealth into the hands of a minority of populations and countries, this is vital. In an era of climate change, biodiversity loss, water stress, soil erosion on unprecedented scales, the need to build conditions for human existence that support and nurture ecosystems health is urgent.

Practical tasks need to be undertaken if the public health movement and professions adopt an ecological public health perspective.

First, ecological public health itself needs to be championed within public health discourse. Reshaping the conditions for good health requires people to do things. That requires, in turn, a combination of leadership and collective action. This requires articulate social movements who 'get' the notions and advantages of ecological public health. That requires education, courses, entry into curricula, teaching and learning. Tony McMichael and colleagues have been too rare as they have charted powerful and inspiring lines of thinking. More programmes of research and development are needed across professional and scientific divides. This function - reaching beyond one's intellectual base camp or primary specialism - is essential for 21 st-century public health. In our own book, we used the unfashionable word 'leadership'. Collegiate thinkers and teamworkers hesitate over leadership for its top-down authoritarian overtones, but what else is there? Champion? Coordinate? Initiate? Cooperate? Pathfinders? Scouts? Pilots? Auditors? Are we speaking of the qualities of individuals or teams, institutions or cultures? Our key point is that within organisations, within laboratories, within research teams, within institutions, within policymaking processes, within movements for ecological public health - anywhere that claims to be interested in health improvement - there must be people in groups who build knowledge, take on the opposing forces, encourage 
and facilitate better integration of human society with our environments. Better match between humans and ecosystems requires change agents. To put it starkly, the world will not change course without change agency.

One of the many reasons we have celebrated Tony McMichael is for his persistent, consistent capacity to supply cogent arguments that question narrow orthodoxy. For us, this is epitomised in his essay on the proximate and distal, a brilliant criticism of conservative thinking, with which we began this chapter. This imaginative leadership of ideas is critical because it has to challenge fragmentary, compartmentalised, departmentalised and uncritical thought. No one's eminence is beyond questioning, if done rationally and by tackling the evidence and the ideas, not the personalities. Who follows and adopts and runs with ideas? Our view is that public health is more than a collection of individuals, however inspired. Individuals matter, but just as science requires a 'community of inquirers', to recall C. S. Peirce's view on progress in science, so too the effective advocacy of ideas requires groups, organisations and movements (Rayner and Lang, 2012).

Although this chapter is written in affectionate homage to a great researcher, thinker and communicator, we end by stressing the word 'public' in ecological public health. Since the 1970s, the world's decision makers and power elite have subscribed broadly to and pursued a neoliberal framework for policy. How their ideas triumphed has been well chronicled elsewhere (Cockett, 1994). Their domination followed the societal perspective of Keynes and the Western architects of post-World War II political economy. Today, the neoliberal domination of political economic thought is, in turn, under stress. Advances in the developing and developed worlds have been threatened. The ruthless accumulation of money and power has been exposed (Tett, 2009). The rewriting of trade rules and conceptual as well as economic boundaries has been highlighted by social movements decrying unfairness. And yet, the primacy of individualism and market forces continues, as though these are concrete realities. In our view, public health is what the term says: the juxtaposition of two words 'health' and 'public'. Public health is about the health of the public. That means more than a vociferous minority of affluent individuals. It refers to collective health; we cannot be healthy if others are not. This requires conditions to be altered, knowing that variations in health will still exist, only the level has been ratcheted up. This societal, nay public, approach to health means societies are judged by how they look after and allow all, not just some, people to live with dignity and decency. Ecological public health is thus the project that has to combine those pursuits with ensuring that the ecosystems on which humanity depends themselves thrive. The 40-year neoliberal project is, to some extent, a block on ecological public health progress. But the intellectual and practical task is much more deeply rooted. 


\section{References}

Boulding, K.E. 1956. General systems theory - the skeleton of science. Management Science 2, 197-208.

Bronfenbrenner, U. 1979. The Ecology of Human Development. Harvard University Press, Cambridge, Massachusetts, USA.

Cockett, R. 1994. Thinking the Unthinkable: Think-Tanks and the Economic Counter-Revolution, 1931-1983. HarperCollins, London, UK.

Corsi, P. 2005. Before Darwin: transformist concepts in European natural history. Journal of the History of Biology 38, 67-83.

Darwin, C. 1859. On the Origin of Species by Natural Selection. John Murray, London, UK.

Dewey, J., Boydston, J.A. \& McDermott, J.J. 2008. John Dewey: The Later Works, 1925-1953: 1935-1937. Southern Illinois University Press, Carbondale, Illinois, USA.

Dissanayake, E. 2009. The artification hypothesis and its relevance to cognitive science, evolutionary aesthetics, and neuroaesthetics. Cognitive Semiotics $5,148-73$.

Dubos, R. 1968. So Human an Animal: How We Are Shaped by Surroundings and Events. Charles Scribner's Sons, New York, USA.

Fogel, R.W. 2004. Technophysio evolution and the measurement of economic growth. Journal of Evolutionary Economics 14, 217-21.

Fogel, R.W. 2008. Forecasting the Cost of U.S. Health Care in 2040. NBER Working Paper No. 14361. National Bureau of Economic Research, Washington, DC, USA.

Gell-Mann, M. 1995. The Quark and the Jaguar: Adventures in the Simple and the Complex. Henry Holt, New York, USA.

Geyer, R.R. 2003. Globalization, Europeanization, complexity, and the future of Scandinavian exceptionalism. Governance 16, 559-76.

Geyer, R.R. \& Rihani, S. 2010. Complexity and Public Policy: A New Approach to 21st Century Politics, Policy \& Society. Routledge, London, UK.

Hamlin, C. 1998. Public Health and Social Justice in the Age of Chadwick: Britain 1800-1854. Cambridge University Press, Cambridge, UK. 
Hancock, T. 2011. It's the environment, stupid! Declining ecosystem health is THE threat to health in the 21 st century (Commentary). Health Promotion International 26, 168-72.

Hanlon, J. 1969. An ecologic view of public health. American Journal of Public Health 59, 4-11.

Her Majesty's Government 2008. Climate Change Act. Available at: www. legislation.gov.uk/ukpga/2008/27/contents, accessed 10 February 2015.

Herbert, S. 2005. Charles Darwin, Geologist. Cornell University Press, New York, USA.

Holland, J.H. 1998. Emergence: From Chaos to Order. Oxford University Press, Oxford, UK.

Institute of Medicine 2002. The Future of the Public's Health in the 21st Century. National Academies Press, Washington, DC, USA.

Institute of Medicine (US) Committee on Health and Behavior: Research Practice and Policy 2001. The Interplay of Biological, Behavioral, and Societal Influences. National Academies Press, Washington, DC, USA.

Jackson, T. 2009. Prosperity without Growth: Economics for a Finite Planet. Earthscan, London, UK.

Kartman, L. 1967. Human ecology and public health. American Journal of Public Health 57, 737-50.

Komlos, J. \& Baur, M. 2004. From the tallest to (one of) the fattest: the enigmatic fate of the American population in the 20th century. Economics \& Human Biology 2, 57-74.

Kricher, J. 2009. Balance of Nature: Ecology's Enduring Myth. Princeton University Press, Princeton, New Jersey, USA.

Lang, T. \& Rayner, G. 2007. Overcoming policy cacophany on obesity: an ecological public health framework for politicians. Obesity Reviews 8, 165-81.

Lang, T. \& Rayner, G. 2012. Ecological public health: the 21st century's big idea? BMJ 345, e5466.

Lang, T., Rayner, G. \& Kaelin, E. 2006. The Food Industry, Diet, Physical Activity and Health: A Review of Reported Commitments and Practice of 25 of the World's Largest Food Companies. Report to the World Health Organisation. City University Centre for Food Policy, London, UK. 
Lauterbur, P.C. 2005. Demystifying biology: did life begin as a complex system? Complexity 11, 30-5.

Love, G.A. 2010. Shakespeare's Origin of Species and Darwin's Tempest. Configurations 18, 121-40.

McKeown, T. 1971. Medical issues in historical demography. In: Clarke, E. (ed.) Modern Methods in the History of Medicine. Athlone Press, London, UK, 5774.

McKeown, T. 1976. The Modern Rise of Population. Edward Arnold, London, UK.

McMichael, A.J. 1999. Prisoners of the Proximate: Loosening the Constraints on Epidemiology in an Age of Change. American Journal of Epidemiology 149, 887-97.

Meadows, D.H., Meadows, D.L., Randers., J. \& Behrens, W.III. 1972. The Limits to Growth: A Report for the Club of Rome's Project on the Predicament of Mankind. Universe Books, New York, USA.

Meadows, D.H., Meadows, D.L. \& Randers, J. 1993. Beyond the Limits: Confronting Global Collapse, Envisioning a Sustainable Future. Chelsea Green Publishing, Post Mill, Vermont, USA.

M'Gonigle, G.C.M. \& Kirby, J. 1936. Poverty and Public Health. Left Book Club ed. Victor Gollancz, London, UK.

Milio, N. 1976. A framework for prevention: changing health-damaging to health-generating life patterns. American Journal of Public Health 66, 435-9.

Mitleton-Kelly, E. (ed.) 2003. Complex Systems and Evolutionary Perspectives on Organisations: The Application of Complexity Theory to Organisations. Emerald Group Publishing, Bingley, UK.

Montoya, J., Pimm, S.L. \& Solé, R.V. 2006. Ecological networks and their fragility. Nature 442, 259-64.

Norberg, J. \& Cumming, G.S. 2008. Complexity Theory for a Sustainable Future. Columbia University Press, New York, USA.

OECD Health Data 2011. How Does the United States Compare. Organisation for Economic Co-operation and Development, Paris, France.

Park, R.E. \& Burgess, E.W. (eds) 1925. The City. University of Chicago Press, Chicago, Illinois, USA. 
Pearce, N. \& Merletti, F. 2006. Complexity, simplicity, and epidemiology. International Journal of Epidemiology 35, 515-9.

Philippe, P. \& Mansi, O. 1998. Nonlinearity in the epidemiology of complex health and disease processes. Theoretical Medicine and Bioethics 19, 591-607.

Popp, J.A. 2007. Evolution's First Philosopher: John Dewey and the Continuity of Nature. State University of New York, Albany, New York, USA.

Rayner, G. \& Lang, T. 2011. Is nudge an effective public health strategy to tackle obesity? No. BMJ 342, d2168.

Rayner, G. \& Lang, T. 2012. Ecological Public Health: Reshaping the Conditions for Good Health. Routledge/Earthscan, Abingdon, UK.

Rescher, N. 1998. Complexity: A Philosophical Overview. Transaction Publishers, New Brunswick, New Jersey, USA.

Richards, R.J. 2006. Nature is the poetry of mind, or how Schelling solved Goethe's Kantian problems. In: Friedman, M. \& Nordmann, A. (eds) The Kantian Legacy in Nineteenth-Century Science. MIT Press, Cambridge, Massachusetts, USA.

Richards, R.J. 2007. Ernst Haeckel's alleged anti-Semitism and contributions to Nazi biology. Biological Theory 2, 97-103.

Rickles, D., Hawe, P. \& Shiell, A. 2007. A simple guide to chaos and complexity. Journal of Epidemiology and Community Health 61, 933-7.

Rothman, D.J. 1997. Beginnings Count: The Technological Imperative in American Health Care. Oxford University Press, New York, USA.

Sandro, G., Chris, H. \& George, A.K. 2009. Social epidemiology and complex system dynamic modelling as applied to health behaviour and drug use research. International Journal of Drug Policy 20, 209-16.

Schabas, M. 2005. The Natural Origins of Economics. University of Chicago Press, Chicago, Illinois, USA.

Schiermeier, Q. 2013. Renewable power: Germany's energy gamble. Nature 496: 156-8. Available at: www.nature.com/news/renewable-power-germany-senergygamble-1.12755, accessed 10 February 2015.

Schwartz, W.B. 1998. Life without Disease: The Pursuit of Medical Utopia. University of California Press, Berkeley, California, USA.

Simms, E.-M. 2005. Goethe, Husserl, and the crisis of the European sciences. Janus Head 8, 160-72. 
Spellberg, B., Guidos, R., Gilbert, D., Bradley, J., Boucher, H.W., Scheld, W.M., et al. 2008. The epidemic of antibiotic-resistant infections: a call to action for the medical community from the infectious diseases society of America. Clinical Infectious Diseases 46, 155-64.

Sterelny, K. 2012. The Evolved Apprentice: How Evolution Made Humans Unique. MIT Press, Boston, Massachusetts, USA.

Stuart, J. 1604. A Counter-blaste to Tobacco. R.B. London, UK archive.org/ stream/acounterblastetol7008gut/17008.txt, accessed 31 March 2015.

Szreter, S. 1988. The importance of social intervention in Britain's mortality decline, c1850-1914. A reinterpretation of the role of public health. Social History of Medicine 1, 1-37.

Szreter, S. 2002. Rethinking McKeown: the relationship between public health and social change. American Journal of Public Health 92, 722-5.

Tansley, A.G. 1935. The use and abuse of vegetational concepts and terms. Ecology 16, 284-307.

Taylor, M.C. 2001. The Moment of Complexity: Emerging Network Culture. University of Chicago Press, Chicago, Illinois, USA.

Tett, G. 2009. Fool's Gold: How Unrestrained Greed Corrupted a Dream, Shattered Global Markets and Unleashed a Catastrophe. Little Brown, London, UK.

Thaler, R. \& Sunstein, C. 2008. Nudge: Improving Decisions about Health, Wealth, and Happiness. Yale University Press, New Haven, Connecticut, USA.

Tsoukas, H. \& Hatch, M.J. 2001. Complex thinking, complex practice: the case for a narrative approach to organizational complexity. Human Relations 54, 979-1013.

Vandenbroucke, J.P., Rooda, H.M.E. \& Beukers, H. 1991. Who made John Snow a hero? American Journal of Epidemiology 133, 967-73.

Weber, T.P. 2007. Alfred Russel Wallace and the antivaccination movement in Victorian England. Emerging Infectious Disease 16, 664-8.

World Health Organization (WHO) 1986. Ottawa Charter. World Health Organisation, Geneva, Switzerland.

WHO 2011. World Health Day 2011: Combat Antimicrobial Resistance. World Health Organisation, Geneva, Switzerland.

Wildavsky, A. 1976. Doing better and feeling worse: the political pathology of health policy. Deadalus 106, 105-23. 
Wilkinson, R.G. \& Pickett, K. 2009. The Spirit Level: Why More Equal Societies Almost Always Do Better. Allen Lane, London, UK.

Williamson, S. 2007. The Vaccination Controversy: The Rise, Reign and Fall of Compulsory Vaccination for Smallpox. Liverpool University Press, Liverpool, UK.

Wilson, E.O. 1998. Consilience. The Unity of Knowledge. Alfred A. Knopf, New York, USA. 
This text is taken from Health of People, Places And Planet:

Reflections based on Tony McMichael's four decades of contribution to epidemiological understanding, edited by Colin D. Butler, Jane Dixon and Anthony G. Capon, published 2015 by ANU Press, The Australian National University, Canberra, Australia. 